\title{
Combustible Wall Lining Materials: Numerical Simulation of Room Fire Growth and the Outline of a Reliability Based Classification Procedure
}

\author{
B. KARLSSON and S. E. MAGNUSSON \\ Department of Fire Safety Engineering \\ Lund University, Sweden
}

\section{ABSTRACT}

An extensive research program on combustible wall lining materials has been carried out in Sweden. A computer model, which as closely as possible describes the physical processes of flame spread and fire growth, is presented using material properties derived from standardized bench-scale tests as input data. These parameters are thermal inertia $\mathrm{k} \rho \mathrm{c}$, flamespread parameter $\phi$, ignition temperature $T_{\mathbf{i g}}$ and RHR-parameters $Q_{\max }^{\prime \prime}$ and $\lambda$. (Time variation of RHR is assumed to be written $\left.Q^{\prime \prime}(t)=Q_{\max }^{\prime \prime} e^{-\lambda t}\right)$. The computer based model simulates the fire growth in the full or $1 / 3$ scale tests, which includes predicting the rate of heat release, gastemperatures, radiation to walls, wall surface temperatures and downward flame spread on the wall lining material. Prediction has been validated against experimental room tests.

When using the computer model for practical purposes an analytical expression summarizing the results of the calculation is highly advantageous.

Applying regression analysis to the computer model results, the following expression was derived for time to flashover

$$
\mathrm{t}_{\mathrm{fo}}=3.08 \cdot 10^{5}(\mathrm{k} \rho \mathrm{c})^{0.75} \phi^{-0.37} \lambda^{0.11}\left(\mathrm{Q}_{\max }^{\prime \prime}\right)^{-0.52}
$$

with the coefficient of determination $\mathrm{R}^{2}=0.98$.

The importance of the expression above is that a material classification criterium has been explicitly expressed as a function of bench scale test results [12]. This opens totally new approaches to a rational material classification. Some of these new avenues are briefly introduced in the paper. 


\section{BACKGROUND}

Recent research on the wall and ceiling lining fire problem in Europe has been heavily influenced by the efforts to produce a harmonisation of "reaction to fire" test methods and of classification systems. It is agreed that a robust and unified classification system must be based on a determination of fire performance requirements and related to hazard assessment. A recent paper enumerates [1] a ten-step procedure for generating the new possible classification system. Among these steps are selection of large scale scenarios, identification of limit states, development of models, based on bench-scale test data, for the prediction of fire growth in the large scale scenario and the establishment of the relationship large scale/bench scale testing. Ideally, it should be possible to define classification criteria in terms of output from bench scale tests such as ignitability, surface spread of flame and heat release rate.

In Sweden, financed by BRANDFORSK, a cooperative research program with these specific objectives has been running through most of the 1980's [2]. This paper gives an incomplete and very summary review of some of the results from this project. Specifically, it refers to the results in two earlier publications $[3,4]$ which should be consulted for necessary detail and additional references.

The purpose of the work presented in [3] and [4] was to use results from bench-scale flammability tests as input to a mathematical model which could rationally predict full scale fire growth on combustible linings. Two scenarios were considered; scenario $\mathrm{A}$, where the lining materials are mounted on compartment walls and ceiling; and, scenario B where the material is mounted on walls only. This paper will consider only scenario B.

In the same Swedish research project previous efforts $[3,13,14]$ to numerically predict fire growth have been directed at scenario A. Generally speaking these models, though varying in complexity, are built on rather simple semi-empirical expressions on flame spread with undetermined parameters calculated by curve fitting. The analysis presented in this paper, in addition to be directed towards scenario B exclusively, is a more detailed and physically based study on the complete fire growth process. It is a "stand-alone" model with no curve fitting required.

The approach used in ref 13 has been further developed within the EURIFIC-project [15] and has been proposed as basis for a future classification procedure [16]. The later part of this paper will outline an alternative procedure.

\section{EXPERIMENTAL BACKGROUND}

\section{Room fire scenario}

Two room sizes will be considered; the full scale test room with a single door opening in accordance with methods proposed by ASTM, ISO and NORDTEST $[16]$; and a $1 / 3$ scale model of the full scale compartment.

The full experimental test series comprise 13 materials, tested in a number of bench-scale methods, in the full-scale version of the ASTM/ISO room corner test and in a $1 / 3$ model scale version. The 13 materials are listed in Table 1. 
The room tests were carried out for two different configurations: with the combustible lining on both walls and ceiling and with the lining on the walls only.

\begin{tabular}{|c|c|c|c|c|c|c|c|}
\hline $\begin{array}{l}\text { Material } \\
\text { no }\end{array}$ & Material name & $\begin{array}{l}Q^{\prime \prime} \max \\
\mathrm{kW} / \mathrm{m}^{2}\end{array}$ & $\begin{array}{r}\lambda \\
s^{-1}\end{array}$ & $\begin{array}{l}\mathrm{k} p \mathrm{c} \cdot 10^{-3} \\
\left(\mathrm{~W} / \mathrm{m}^{2} \mathrm{~K}\right)^{2 \mathrm{~s}}\end{array}$ & $\begin{array}{c}\phi \\
(\mathrm{m} / \mathrm{s}) \mathrm{K}^{2}\end{array}$ & $\begin{array}{l}\text { Thicknes } \\
\mathrm{kg} / \mathrm{m}^{3}\end{array}$ & Density \\
\hline l & Insulating fiberboard & 140 & 0.0070 & 41 & 63 & 13 & 250 \\
\hline 2 & $\begin{array}{l}\text { Medium density fiber- } \\
\text { board }\end{array}$ & 162 & 0.0027 & 80 & 15 & 12 & 600 \\
\hline 3 & Particle board & 200 & 0.0049 & 110 & 14 & 10 & 750 \\
\hline 4 & Gypsun plasterboard & 28 & 0.0150 & 100 & - & 13 & 700 \\
\hline 5 & $\begin{array}{l}\text { PVC cover on gypsum } \\
\text { plboard }\end{array}$ & 107 & 0.0293 & 75 & - & $0.7+13$ & 680 \\
\hline 6 & $\begin{array}{l}\text { Paper cover on gypsum } \\
\text { pl.board }\end{array}$ & 105 & 0.0208 & 100 & 1 & $0.6+13$ & 680 \\
\hline 7 & $\begin{array}{l}\text { Textile cover on gypsurn } \\
\text { plboard }\end{array}$ & 222 & 0.0278 & 80 & 16 & $0.7+13$ & 690 \\
\hline 8 & $\begin{array}{l}\text { Textile cover on mineral } \\
\text { wool }\end{array}$ & 246 & 0.0382 & 4.3 & 46 & $0.7+42$ & 180 \\
\hline 9 & $\begin{array}{l}\text { Melamine faced particle } \\
\text { board }\end{array}$ & 41 & 0.0032 & 105 & - & $1.2+1.3$ & 810 \\
\hline 10 & Expanded polystyren & - & - & - & -- & 50 & 20 \\
\hline 11 & Rigid polyuretlane foam & 130 & 0.0217 & 4.0 & - & 30 & 30 \\
\hline 12 & Wood panel, spruce & 150 & 0.0080 & 85 & 44 & 11 & 530 \\
\hline 13 & $\begin{array}{l}\text { Paper cover on particle } \\
\text { board }\end{array}$ & 164 & 0.035 & 110 & 19 & $0.6+1.0$ & 730 \\
\hline
\end{tabular}

For scenario A all 13 materials were tested in the full-scale room test. For scenario B, materials 2, 3, 6 and 8 were tested in full-scale. All 13 materials were tested in the $1 / 3$ scale model room, though.

Bench scale test output

Bearing in mind that the objective was limited to explore the potential of the ISO ignitability, surface spread of flame and heat release rate tests, the problem then becomes to decide in the appropriate methodology to process output data from these bench scale tests and derive flammability parameters required by the numerical submodels. The procedures that were utilized are briefly described below.

\section{Ignitability test}

The 13 materials listed in table 1 were tested in the Standard ISO ignitability test. With additional thermocouples attached to both sides of the sample the test can be used to derive parameters such as thermal conductivity, $k$, and thermal capacity, $k \rho c$, of the tested specimen. The values of thermal inertia, $\sqrt{\mathrm{k} \rho \mathrm{c}}$, used in this study were derived in this way and are listed in Table 1. A full description of the method used to derive these parameters is given in [3].

For all room fire experiments time to ignition was closely correlated to the 
ignition times measured in the ISO ignitability apparatus [3]. Details of this correlation are given in [4].

Surface spread of flame test

The 13 materials listed in Table 1 were tested in the IMO and ISO surface spread of flame tests. The flame spread parameter $\phi$ was experimentally determined according to the procedures described in e.g. Harkleroad, Quintiere and Walton ${ }^{5}$, see Table 1 .

Rate of Heat Release measurements

The 13 materials were tested in three different RHR apparatuses: the Ohio State University apparatus, an open configuration based on a design originally developed by the National Institute of Standards and Technology (formely National Bureau of Standards) [6], and the cone calorimeter.
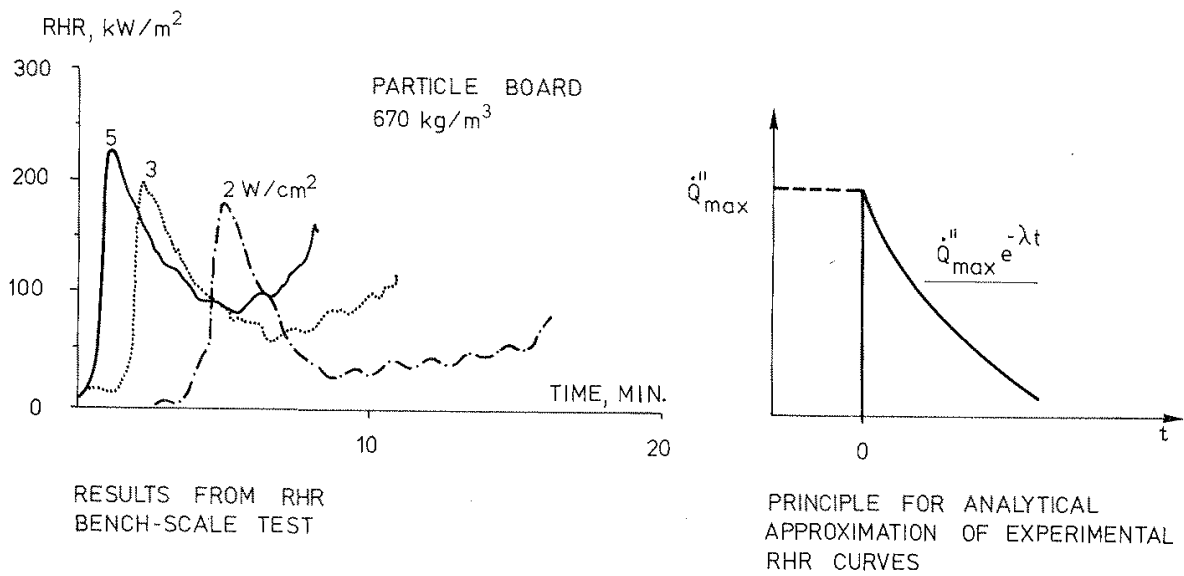

Figure 1

The experimental curves were idealized as seen in Fig. 1, resulting in the expression

$Q^{\prime \prime}(\mathrm{t})=Q^{\prime \prime} \max ^{\mathrm{e}^{-\lambda \mathrm{t}}}$

The $Q^{\prime \prime}$ max values were taken directly from measurements and are given together with the corresponding regression values of $\lambda$ in Table 1. Equation (1) seemed phenomenologically correct except for material 10 .

\section{MAIN MODEL STRUCTURE}

The total rate of heat release in the room is assumed to come from five sources; the gasburner, the vertical wall area behind the burner, a horizontal strip of material at the ceiling/wall intersection corresponding to the vertical height of the ceiling jet and, when downward flame spread has started, the wall material in the upper layer and from the wall linings below the hot gas layer, respectively. 
The following submodels are included in the total simulation model

1. Ignition of wall area behind burner, using data from the ISO ignitability test

2. Horizontal, concurrent flame spread along intersection ceiling/walls

3. Upper layer hot gas temperature calculation based on calculated HRR

4. Heating up of wall areas, both below and above the thermal discontinuity, by convection and radiation

5. Downward, against the wind, flame spread

6. Calculation of total heat release rate, based on areas pyrolyzing and time dependence of bench scale HRR curves

\section{SUBMODELS IN THE NUMERICAL SIMULATION COMPUTER PROGRAM}

Most of the submodels listed above have been described in detail in [4] and will therefore not be discussed in this paper. However, recent improvements in the model include the calculation of horizontal concurrent flame spread along the ceiling/wall intersection. This submodel will therefore be discussed in some detail.

Flamespread along wall/ceiling intersection

Once the material behind the burner ignites, the flames hit the ceiling and stretch out along the ceiling/wall intersection. After a heating up period the material behind the flames ignites and the flame spreads along the intersection in the mode of concurrent flame propagation.

Saito, Quintiere and Williams [7] introduced the following Volterra type integral equation for concurrent flow flame spread velocity $V_{p}(t)$

$$
\begin{aligned}
& \mathrm{V}_{\mathrm{p}}(\mathrm{t})=\mathrm{V}_{\mathrm{po}}+\frac{1}{\tau}\left[\int_{0}^{\mathrm{t}}\left(\mathrm{kq \dot {m } ^ { \prime \prime }}\left(\mathrm{t}-\mathrm{t}_{\mathrm{p}}\right)-1\right) \mathrm{V}_{\mathrm{p}}\left(\mathrm{t}_{\mathrm{p}}\right) \mathrm{dt} \mathrm{p}_{\mathrm{p}}-\mathrm{kqx}_{\mathrm{po}}\left(\dot{\mathrm{m}}^{\prime \prime}(\mathrm{o})-\dot{\mathrm{m}}^{\prime \prime}(\mathrm{t})\right)-\right. \\
& \left.\mathrm{k}\left(\mathrm{Q}_{\mathrm{o}}^{\prime}(\mathrm{o})-\mathrm{Q}_{\mathrm{o}}^{\prime}(\mathrm{t})\right)\right]
\end{aligned}
$$

where $\tau$, the characteristic ignition time, is written as

$$
\tau=\frac{\pi \mathrm{k} \rho \mathrm{c}\left(\mathrm{T}_{\mathrm{p}}-\mathrm{T}_{\mathrm{a}}\right)^{2}}{4 \cdot \dot{\mathrm{q}}_{\mathrm{f}}{ }^{2}}
$$

$q \dot{m}$ " signifies the HRR per unit width of lining material, $Q_{0}^{\prime}$ the pilot flame energy release rate per unit width, $T_{p}$ is pyrolyzation temperature, $x_{\text {po }}$ is initial pyrolysis length, $V_{p o}$ the initial pyrolysis velocity and $\dot{q}_{f}^{\prime \prime}$ is forward heat transfer from flame.

Thomas and Karlsson [8] discussed the assumptions and limitations behind this approach and gave analytical solutions to equation (2) for certain conditions, 
depending on flame length correlations, initial gas burner output and the rate of heat release history of the burning material.

The analytical solution used here is given as

$V_{h}(t)=\frac{1}{X_{1}-X_{2}}\left[\left(B+A X_{1}\right) e^{X_{1} t}-\left(B+A X_{2}\right) e^{X_{2} t}\right]$

where $A=\frac{k}{\tau}\left[Q^{\prime \prime} \max \cdot A_{W} e^{-\lambda \tau}+Q^{\prime \prime} \max \cdot W \cdot X_{p o}-\frac{L_{o}}{k}\right]$

$\mathrm{B}=-\frac{\mathrm{L}_{0} \lambda}{\tau}, \mathrm{C}=\frac{1}{\tau}\left(\tau \lambda-\mathrm{k} \mathrm{Q}^{\prime \prime}{ }_{\max } \cdot \mathrm{W}+1\right), \mathrm{D}=\frac{\lambda}{\tau}$

$X_{1}=\frac{1}{2}\left(-C+\sqrt{C^{2}-4 D}\right), X_{2}=\frac{1}{2}\left(-C-\sqrt{C^{2}-4 D}\right)$

$\mathrm{V}_{\mathrm{h}}$ refers to the horizontal flame spread velocity in the ceiling/wall intersection, $Q^{\prime \prime}{ }_{\max } A_{W} e^{-\lambda \tau}$ is the heat release rate from the wall area $A_{W}$ behind the burner at the onset of concurrent flame propagation and $W$ is the width of the burning strip in the ceiling/wall intersection, here taken to be around $5 \%$ of the room height. $\mathrm{k}$ and $\mathrm{L}_{0}$ are flame length correlation constants described by Thomas and Karlsson [9] who used data from Gross [10] to express the length of flames under ceilings as a function of heat release $Q$, ceiling height $\mathrm{H}$, and burner diameter $\mathrm{D}$.

Calculation of upper layer gas temperature

Gastemperatures were calculated according to the well known expression [11]

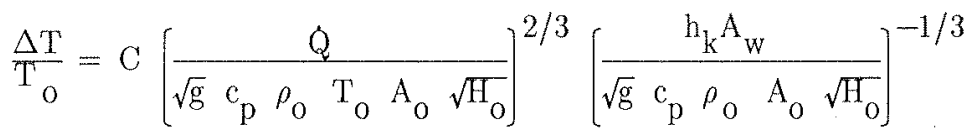

It proved necessary to introduce a maximum limit on $Q$ based on air entrainment into the wall flame. With this complement the expression above works satisfactorily for all tests.

Heat transfer to walls etc

One long side of the compartment wall was split into a large number of thin, horizontal strips and the heat flux from the gas layer to the center of each strip calculated using standard expressions. Once the downward flame spread started, the radiation from the wall flames and the pyrolysing lining material behind the flames was added to the smoke layer radiation.

For the part of the wall lining surface submerged in the upper hot gas layer, heat transfer and surface temperature were calculated using traditional 
procedures. Calculated and measured wall-surface temperatures were compared in [4], showing good agreement.

Downward flame spread

The downward flame spread velocity, $V_{d}$, is calculated from the expression

$\mathrm{V}_{\mathrm{d}}(\mathrm{t})=\frac{\phi}{\left(\mathrm{T}_{\mathrm{p}}-\mathrm{T}_{\mathrm{S}}\right)^{2}}$

where $\mathrm{T}_{\mathrm{p}}=$ pyrolyzation temperature, $\mathrm{T}_{\mathrm{S}}=$ surface temperature at flame front.

Calculation of total heat release rate

RHR, full scale test, scenario B

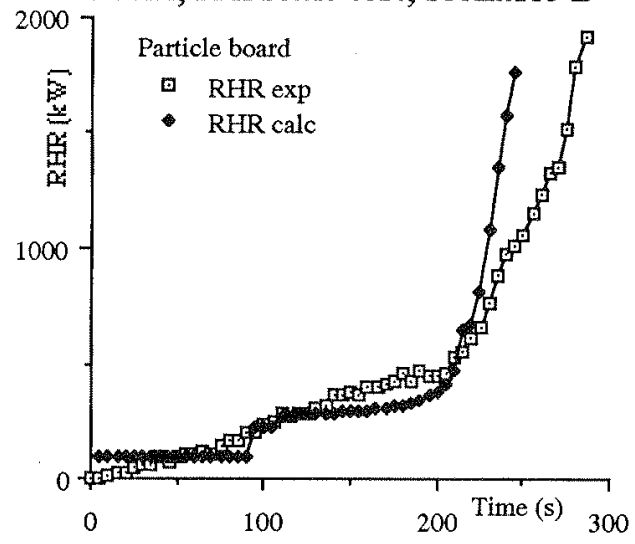

Figure 2.

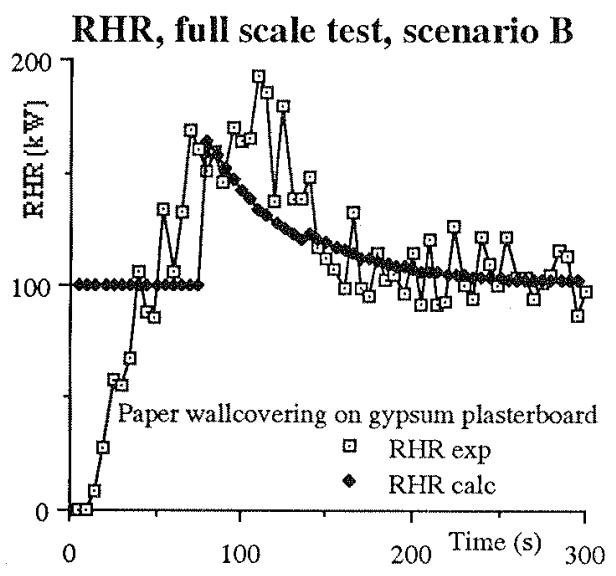

Figure 3.

The total rate of heat release, $Q_{\text {tot, }}$, at time $t$ (counted from time $t_{\text {start }}+$ $\tau$ ) then becomes (with $\mathrm{t}_{\mathrm{p}}$ as dummy integration variable)

$Q_{t o t}(t)=Q_{g b}+Q^{\prime \prime} \max _{w} A^{-\lambda(t+\tau)}+Q^{\prime \prime}{ }_{\max } W\left[x_{p o} e^{-\lambda t}+\int_{0}^{t} e^{-\lambda(t-t} p\right)$

$\left.\mathrm{V}_{\mathrm{h}}\left(\mathrm{t}_{\mathrm{p}}\right) d \mathrm{t}_{\mathrm{p}}\right]+\mathrm{Q}^{\prime \prime} \max L\left[\int_{0}^{\mathrm{t}} \mathrm{e}^{-\lambda\left(\mathrm{t}-\mathrm{t}_{\mathrm{p}}\right)} \mathrm{V}_{\mathrm{d}}\left(\mathrm{t}_{\mathrm{p}}\right) d \mathrm{t}_{\mathrm{p}}\right]$

where $L$ is the length of the strip over which the downward flame spreads and 
$\mathrm{A}_{\mathrm{W}}$ is the area of burning material behind the gas burner.

The first term is the effect from the gas burner, the second the contribution from the wall behind the burner and the third from the part of the horizontal strip which is pyrolysing.

The fourth and final term in Equation 6 is the contribution of the downward flame spread in the upper layer and, once the flames reach the intersection of the hot gas layer and the lower ambient layer, the downward flame spread below the hot layer.

Figure 2 shows the results of using this procedure on material 3 in Table 1 for the full scale test. Figure 3 shows the results of using the procedure on a material which does not go to flashover, i.e. material 6 in table 1 . The procedure has been used on other materials, in both full and $1 / 3$ scale tests, showing similar results.

Summing up, a model numerically simulating the fire growth process and based on the bench-scale test parameters $k \rho c, \phi, \mathrm{T}_{\mathrm{ig}}, \mathrm{Q}^{\prime \prime}{ }_{\max }$ and $\lambda$ has been developed and at least partially validated [4].

\section{A RATIONAL CLASSIFICATION PROCEDURE}

\section{Derivation of analytical expression for $t_{f_{0}}$}

If we want the validated computer model outlined above to be a basis for material classification a number of fundamental questions must be asked:

* which are the most important of the enumerated variables and what happens if we leave one out?

* how does the uncertainty or variability inherent in the determination of the material flammability characteristics affect the overall reliability of the classification procedure?

* how is classification reliability affected by computer modelling uncertainty?

To even start considering the answers to questions such as these requires extensive sensitivity testing and a prohibitive amount of calculation.

It is clear that in practice the entire classification would be greatly facilitated if the limit state could be expressed as an analytical function of design parameters.

To test the idea the following expression was written

$\mathrm{t}_{\text {fo }}=\mathrm{a}_{\mathrm{o}}(\mathrm{k} \rho \mathrm{c})^{\mathrm{b}_{1}} \phi^{\mathrm{b}_{2}} \mathrm{~T}_{\mathrm{ig}}{ }^{\mathrm{b}_{3}}\left(\mathrm{Q}^{\prime \prime}{ }_{\max }\right)^{\mathrm{b}_{4}} \lambda^{\mathrm{b}_{5}}$

and the constant $a_{0}$ and the exponentials $b_{1} \ldots b_{5}$ determined by linear regression 
analysis, using the computer program to calculate several hundreds of values of $t_{\text {fo }}$ for the $1 / 3$ scale test series.

Disregarding the influence of $\mathrm{T}_{\mathrm{ig}}$ (the range of variation is rather limited) the resultant expression was

$\mathrm{t}_{\text {fo }}=3.08 \cdot 10^{5}(\mathrm{k} \rho \mathrm{c})^{0.75} \phi^{-0.37} \lambda^{0.11}\left(\mathrm{Q}_{\max }\right)^{-0.52}$

with the coefficient of determination $\mathrm{R}^{2}=0.98$. Standard error of estimate was 0.075. A comparison between the analytical expression for $t_{\text {fo }}$ above and results from the computer model is given in Fig. 4. For flashover times up to $800 \mathrm{~s}$ expression $7 b$ gives a very good representation of the computer model.

\section{Time to flashover, model vs. regression equation}

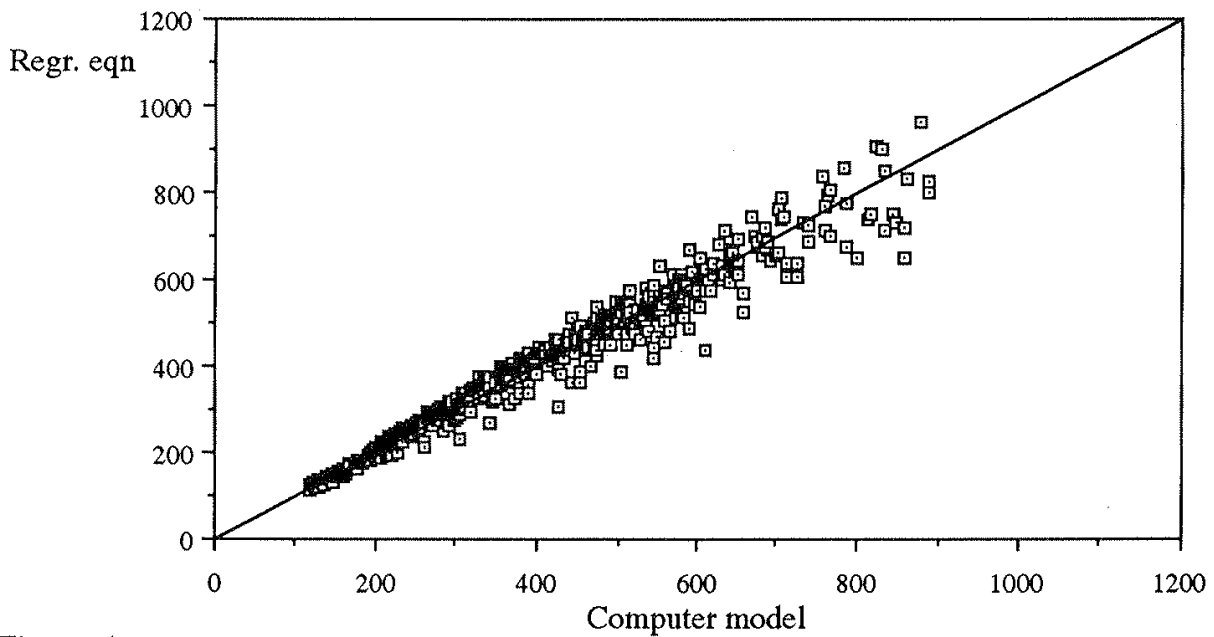

Figure 4.

A similar expression can be obtained to calculate the maximum rate of heat release in room fires when flashover does not occur. The result of a preliminary correlation is

$\operatorname{Max} R H R=8.56 \times 10^{-5} \cdot(\mathrm{k} \rho \mathrm{c})^{-0.3} \phi^{1.06} \lambda^{-0.93}\left(\mathrm{Q}_{\max }^{\prime \prime}\right)^{0.93}$

with a coefficient of determination $R^{2}=0.92$.

Alternative representation of flammability parameters, future work

The flammability parameters $\mathrm{k} \rho \mathrm{c}, Q_{\max }^{\prime \prime}$ and $\lambda$ were originally developed for the work described in ref 3 . Especially the use of $Q^{\prime \prime}(t)=Q_{\max }^{\prime \prime} e^{-\lambda t} \operatorname{might}$ create problems in routine classification work although it should be recognized 
that heat release curves from all the 13 materials tested (except polystyrene) could be expressed in this way with acceptable precision. On the other hand, unambiguous derivation procedure of $Q_{\max }^{\prime \prime}$ and $\lambda$ may be hard to standardize

and a direct use of $Q^{\prime \prime}(\mathrm{t})$ would clearly be preferrable. For the computer model, this is mainly a question of making programming changes. Regarding the analytical regression equation, Thomas and Karlsson [17] very recently pointed out that in Equation $7 \mathrm{~b}$ the combination of $Q_{\max }^{\prime \prime}$ and $\lambda$ is

$t_{\text {fo }} \sim\left[\frac{Q^{\prime \prime} \max }{\lambda^{0.21}}\right]^{-0.52}$

The bracketed term is obtained by integrating a weighted heat release

$\mathrm{I}_{\mathrm{Q}}=\int_{0}^{\infty} \frac{Q_{\max }^{\prime \prime} \mathrm{e}^{-\lambda t}}{\mathrm{t}^{0.79}} \mathrm{dt}$

which strongly suggests that an alternative form might be

$\mathrm{I}_{Q}=\int_{0}^{\infty}\left[\frac{\mathrm{Q}^{\prime \prime}(\mathrm{t})}{\mathrm{t}^{0.79}}\right] d t$

with $Q^{\prime \prime}(t)$ directly taken from the cone calorimeter. Replacing $k \rho c$ with time to ignition tig, also directly obtained from the bench-scale test, should be straight forward.

Work along all these lines is now (March 1991) continuing as well as efforts, in a wider context, to implement these results in a classification procedure with regard taken to uncertainty, reliability and economy.

\section{ACKNOWLEDGEMENTS}

This paper is a result of a research project, "The pre-flashover fire", financed by the Swedish Fire Research Board (BRANDFORSK) whose assistance is gratefully acknowledged.

Participating organisations are the Swedish National Testing Institute, the Swedish Institute for Wood Technology Research and the Department of Fire Safety Engineering, Lund University. Main project leader is Ove Pettersson. Sven Erik Magnusson is leader for those parts of the project carried out at Lund University. Björn Karlsson is responsible for model building, computer programming and analysis of results.

Particular thanks are due to Professor Philip H. Thomas for his contributions on concurrent flame spread, flame lengths under ceilings and the weighting of heat release rate. 


\section{REFERENCES}

1. Vandevelde, P., Transitional Arrangements for Reaction to Fire Testing in Europe, Annex 1, CEC III B-5 Document TC2/002 Brussels, 26 January 1990

2. Pettersson, O., Fire Hazards and the Compartment Fire Growth Process Outline of a Swedish Joint Research Program, FoU-brand No 1, 1980

3. Magnusson, S.E., Sundström, B., Combustible Linings and Room Fire Growth - A First Analysis, Report LUTVDG/(TVBB 3030), Department of Fire Safety Engineering, Lund University, Lund 1985. Also in ASTM STP 882, T.Z. Harmathy, Editor, ASTM Philadelphia 1985, pp 45-69

4. Karlsson, B., Room Fires and Combustible Linings, Department of Fire Safety Engineering, Lund University, October 1989

5. Harkleroad, M., Quintiere, J., Walton, W., Radiative Ignition and Opposed Flow Flame Spread Measurements on Materials, Report No. DOT/FAA-CT-83/28, FAA Technical Center, Atlantic City Airport, N.J., 1983

6. Sensenig, D.L., An Oxygen Consumption Method for Determining the Contribution of Interior Wall Finishes to Room Fires, NBS Technical Note 1128, National Bureau of Standards, Washington DC, 1980

7. Saito, K., Quintiere, J.G., Williams, F.A., Upward Turbulent Flame Spread, Int. Assoc. for Fire Safety Science, Fire Safety Science Proceedings, 1st Int. Symposium October 7-11 1985, Grant, C.E. and Pagni, P.J., Editors, Gaithersburg, MD, Hemisphere Publishing Corp, New York, 1985

8. Thomas, P.H., Karlsson, B., On Upward Flame Spread, Dept. of Fire Safety Engineering, Lund University. To be published.

9. Thomas, P.H., Karlsson, B., On the Length of Flames Under Ceilings, Dept. of Fire Safety Engineering, Lund University. To be published.

10. Gross, D., "Measurements of Flame Lengths Under Ceilings". NISTIR 88-3835, National Institute of Standards and Technology, Washington DC, 1988 .

11. McCaffrey, B.J., Quintiere, J.Q., Harkleroad, M.F., Estimating Room Temperatures and the Likelyhood of Flashover Using Fire Test Data Correlations. Fire Technology, Vol 17, pp 98-119, 1981

12. Karlsson, B., Magnusson, S.E., Andersson, B., Numerical Simulation of Room Fire Growth on Combustible Linings and a Rational Classification Procedure, Proceedings of the $\mathrm{V}$ International Interflam Conference, Interscience Communcations Limited, London, 1990.

13. Wickström, U., Göransson, U., Prediction of Heat Release Rates of Surface Materials in Large-Scale Fire Test Based on Cone Calorimeter Results, ASTM Journal of Testing and Evaluation, Vol 15, No 6, nov 1987. 
14. Östman, B., Nussbaum, R., Correlation between Small-Scale Rate of Heat Release and Full-Scale Room Flashover for Surface Linings, Sec. symposium of the International. Association for Fire Safety Science (IAFSS), Tokyo, 1988.

15. EUREFIC-programme, A joint Nordic research programme for developing new fire test methods and classification criteria for wall and ceiling linings, Statens Provningsanstalt, Borås, Sweden, 1989.

16. Sundström, B., Göransson, U., Possible Fire Classification Criteria and Their Implications for Surface Materials Tested in Full Scale According to ISO DP 9705 or NT FIRE 025, SP-Report 1988:19, Borås, Sweden.

17. Thomas, P.H. and Karlsson, B., Dimensionless Quantitites in Fire Growth: The Weighting of Heat Release Rate, SE-LUTVDG/TVBB-3057, Department of Fire Safety Engineering, Lund University, Dec 1990. 